\title{
Current Status of Xenotransplantation
}

\author{
Richard N. Pierson III \\ Department of Surgery, Baltimore VAMC, and Division of Cardiac Surgery, University of \\ Maryland, Baltimore, Maryland, USA
}

\section{Keywords}

Antibody-mediated rejection; a 1,3-galactosyltransferase gene-knockout (GalT-KO); Coagulation; Genetic engineering, pig; Pancreatic islets, pig; Pig; Xenotransplantation

Transplantation improves quality of life and saves tens of thousands of lives each year. However, the supply of human organs and tissues is insufficient to treat all patients who qualify for kidney, liver, islet cell, pancreas, heart, or lung transplantation. These considerations provide a powerful impetus motivating early clinical introduction of crossspecies or "xeno" transplantation.

Pigs have been developed as a potential xenograft source species based on various physiologic and logistical considerations. (1) Use of non-human primates is not feasible for a number of reasons, ethical concerns prominent among them, and because the risk of a nonhuman primate virus causing epidemic human disease is not acceptable. (2) Recently, a clinical islet xenograft trial involving 8 patients with diabetes and using porcine pancreatic cells has obtained provisional approval by New Zealand regulatory authorities. (3) This Commentary discusses scientific benchmarks and ethical predicates necessary prior to clinical xenotransplant trials.

\section{Organ-specific considerations}

\section{Heart and Kidney}

Experimental xenotransplantation using pig hearts and kidneys in pharmacologically immunosuppressed primates has made important progress over the past two decades based primarily on genetic modification of source animals. (1) Adding protective human "complement regulatory" genes to the pig confers significant protection from complementmediated organ xenograft injury. Similarly, removing the most important pig carbohydrate antigen recognized by humans, Galactose $1,3 a$ Galactose (Gal 1,3a Gal), by "knock-out" of the a-1,3 galactosyltransferase gene ("Gal knock-out", or GalT-KO), is associated with the longest individual pig kidney (12 week) and heart (6 month) survivals yet achieved in nonhuman primates. $(4,5)$

However injury to these transgenic grafts is not readily controlled using current treatment regimens, and the importance of contributing factors remains unclear. $(6,7)$ There is good evidence that traditional immune rejection mechanisms damage the graft. Thus T-cell or antibody immune responses targeted against pig molecules other than Gal 1,3a Gal may mediate the "delayed xenograft rejection" and "thrombotic microangiopathy" observed in long-surviving xenografts. Alternatively, molecular incompatibilities between pig and 
human proteins may contribute to physiologically important non-immune disturbances in coagulation and vascular biology.

Multiple differences have been identified in complement or coagulation pathway protein function between pigs and humans. (1) It seems likely that one or more of these incompatible molecular interactions contributes to clot formation within graft vessels, even under circumstances in which evidence for immune injury is weak. (8) GalT-KO pigs that express human complement, coagulation pathway regulatory proteins, or both are currently undergoing preclinical evaluation based on evidence that both of these mechanisms participate in pig organ xenograft injury. If organ xenograft injury is effectively controlled by expression of human coagulation or complement regulatory proteins, these modifications may yield a pivotal advance toward clinical application.

Preoperative induction of tolerance to pig antigens based on pig bone marrow or stem cell transplantation is a promising strategy that is hoped will one day avoid the need for longterm immunosuppression. The pig donor can be identified in advance, and the surgical procedure performed once stable mixed hematopoetic chimerism is achieved. So far, rapid clearance of pig hematopoetic cells after infusion into baboons has posed a stubborn barrier to this approach. (1)

\section{Liver Xenografts}

Timely support of patients with liver failure is a significant unmet clinical need. Extracorporeal perfusion using either wild-type or complement transgenic pig livers $(9,10)$ is associated with neurologic improvement in patients with hepatic failure and with successful bridging to transplant or recovery of the native liver. GalT-KO pig livers, with or without additional genetic modifications, have not yet been tested, but may be promising for achieving therapeutic function and improved durability. Extracorporeal liver perfusion in humans with hepatic failure would provide a relatively low-risk opportunity to study various immunologic and biochemical xeno-interactions, and yield new knowledge potentially important to success in other areas of xenotransplantation.

\section{Islet xenografts}

Significant progress has been made toward clinical trials of pig islet transplantation. Wildtype porcine islets have reversed experimentally induced diabetes for up to 6 months in cynomolgus macaques (11) and almost 9 months in rhesus monkeys (12). Although the immunosuppression used for these studies was more intensive than most clinicians and human patients would find acceptable, these studies demonstrate consistent, prevalent longterm insulin independence for the first time in pig-to-primate models. Preliminary data using islets from genetically modified pigs and with islet encapsulation (DKC Cooper and P Gianello, personal communications) suggest that a clinically acceptable regimen could soon be developed for clinical islet xenotransplantation.

\section{Infectious Disease Risks}

An important concern for clinical xenotransplantation is that a latent pig virus or another infectious agent could infect an immunosuppressed organ xenograft recipient and cause disease. $(1,13)$ Some experts consider it likely that infection of a xenograft recipient with a porcine organism will occur. If this infection could be transmitted among humans by close contact or other means - and particularly if the infection did not cause obvious symptoms it could spread undetected into the community. It is encouraging that to date, infection with porcine endogenous retrovirus has not been detected in humans or other primates exposed to living pig cells and tissues, even with immunosuppression. Infection of human cells by porcine endogenous retrovirus (PERV) does not occur readily under most experimental 
conditions. Thus the risk of significant recipient disease or contagion appears to be small, and may be acceptable when weighed against the potential benefits to both transplant candidates and society at large of expanded access to life-saving transplants. Importantly, systematic, life-long recipient surveillance and archiving of donor and recipient specimens is prudent to limit societal risk by early detection of known or unknown organisms in case a suspicious syndrome in xenograft recipients or their close contacts justifies epidemiologic investigation.

\section{Ethical and Logistical Considerations}

Individuals, societies, and cultures generally consider that xenotransplantation is compatible in principle with their religious and moral beliefs. However, public awareness about xenotransplantation is low. Public confidence can best be earned and sustained by publicizing scientific progress that offers convincing preclinical evidence for likely clinical efficacy, as judged by deliberate, rigorous peer review. Peer-reviewed ethical and scientific guidelines for clinical xenotransplantion have been published. $(1,14)$ Once clinical efficacy in humans seems likely for a particular xenograft application, clinical trial designs should be vetted through a transparent national regulatory process designed to assure safe, ethically sound, and culturally appropriate trial conduct. Informed consent and education processes must take into account not only the risks and potential benefits to the experimental participant, as well as implications for and obligations incurred by close contacts and the community at large.

\section{Current Key Barriers to Xenotransplantation}

Based on the current understanding of the residual barriers to xenotransplantation, significant progress in any one of four key areas is likely to catalyze progress to successful clinical trials of cell and organ xenotransplantation.

1. Determine the number, nature (carbohydrate or protein), and relative importance of non-Gal porcine "antigen" targets recognized by the human immune system. This knowledge will allow approaches to be devised to control the immune response to the most important of these antigens. "Tolerance" to several "immunodominant" pig proteins may confer protection of the entire graft from immune injury by converting pathogenic responses directed at those targets to dominant protective effects.

2. Improve protection of pig grafts from injury based on genetic modifications to the pig. To better protect pig tissues from antibody-mediated and coagulation-mediated injury, GalT-KO pigs have been created with additional human 'anticoagulant' genetic modifications, 'anticomplement' regulatory genetic modifications, or both, to prevent "humoral" (non-cellular) graft injury. Additional modifications may also be necessary to prevent injury by NK- or macrophage-mediated "cellular" immune injury.

3. Develop more effective, less toxic approaches to control immune responses to xenoantigens. More selective immunomodulatory or immunosuppressive approaches to inhibit "adaptive" T- and B-cell immune responses to xenoantigens could widen the therapeutic window for xenografts, and facilitate cross-species tolerance. Wherever possible, these approaches will be based on immunoisolation (a technique that probably is applicable only to islets), or special vulnerabilities in the anti-xeno response, such as the unusually critical dependence of anti-xeno responses on CD4+ T-cell "help" and "costimulation". $(1,15)$ 
4. Define and control pathogenic cell-cell interactions unique to the pig-to-primate combination. Improved understanding of idiosyncratic cross-species interactions should allow overcoming technical barriers to transfer of living cells from pig to humans and non-human primates. This would facilitate islet transplantation, and pre-transplant tolerance induction strategies based on stem cell transfer and "mixed hematopoietic chimerism". Similarly inhibition of pig liver sequestration of human erythrocytes and other cells during ex vivo perfusion could facilitate use of pig livers to avoid transplantation or improve recipient condition at transplant in critically ill patients.

Survival of primates with life-supporting pig cardiac, renal and islet xenografts for 1,3 , and 8.5 months, respectively, suggests that physiologic, biochemical, or neurohumoral incompatibilities are unlikely to pose a significant problem for porcine xenograft recipients once immunologic barriers are overcome. (1)

\section{Comment}

It is essential that 1) for any clinical xenograft trial, the study design must be based on peerreviewed objective evidence from primate studies that efficacy is likely relative to the best available alternative; 2) public health mechanisms must be in place to protect patients who choose to participate initials and to defend the public at large from unlikely but potentially serious risk; and 3) ethical and moral guidelines must be followed that are consistent with both locally agreed procedures and guidance published by WHO and international professional societies.

While the plight of patients with severe, brittle diabetes and end-stage organ failure is a powerful spur to early clinical trials, the potential risks to experimental participants and to society at large require that highest scientific and ethical standards be consistently applied before proceeding with any clinical xenograft trial. Once a consistently effective, clinically tolerable immunosuppressive regimen is developed in primates, clinical xenografts may first be used in selected patient groups who are unlikely to receive allografts. In addition to patients at high risk for serious complications from diabetes, xenografts might be appropriately considered for highly "sensitized" (having antibodies against most MHC alloantigens) renal patients without secure dialysis access, or in sensitized end-stage heart failure patients with a contraindication to systemic anticoagulation.

Clinical trials ongoing in Russia and provisionally approved for New Zealand (3) lack adequate published scientific evidence from non-human primates that patients are likely to benefit significantly. On the other hand the New Zealand health regulatory authority has undertaken a deliberate public consultative process regarding trial conduct, consent procedures, and public health concerns, such as health monitoring and tissue archiving for study participants and close contacts. Whatever the outcome, clinical trials conducted in this regulatory context are likely to build public confidence in xenotransplantation.

Proximate advances in technology - including refinement of immunosuppression and further genetic modifications to the pig - may soon prove sufficient to translate the promise of xenotransplantation into a viable therapeutic option. Although recent progress is significant, further advances are required to justify broad support for human trials within the scientific community, and as a predicate to clinical trial approval by government regulatory and ethical bodies. Acceptance by an informed public and early clinical success are both much more likely if this path is consistently followed. 


\section{Acknowledgments}

The author acknowledges contributions to this manuscript by Anthony Dorling, Michael A. Rees, Bernhard J. Hering, David K.C. Cooper, They and their many colleagues, past and present, provided the scientific and ethical foundation for this manuscript.

Dr. Pierson has received research support from the American Heart Association, VA Merit Program, Office of Naval Research, American Society of Transplant Surgeons, University of Maryland General Clinical Research Center (M01 RR016500), National Institutes of Health (NIH: UO1 AI066335 and U01 AI066719), and Revivicor, Inc.; is President of the International Xenotransplantation Association; and serves on the scientific advisory board of Revivicor, Inc.

\section{Abbreviations and definitions}

$\begin{array}{ll}\text { GalT-KO } & \text { a1,3-galactosyltransferase gene-knockout } \\ \text { Gal 1,3aGal } & \text { Galactose } 1,3 \mathrm{a} \text { Galactose } \\ \text { PERV } & \text { porcine endogenous retrovirus } \\ \text { MHC } & \text { major histocompatibility complex }\end{array}$

\section{REFERENCES}

1. Cooper DKC, Dorling A, Rees M, Seebach J, Yazer M, Ohdan H, Awwad M, Ayares D, Pierson RN III. a 1,3-galactosyltransferase gene-knockout pigs: where do we go from here? Transplantation. 2007; 84(1):1-7. [PubMed: 17627227]

2. Allan JS. The risk of using baboons as transplant donors. Exogenous and endogenous viruses. Ann N Y Acad Sci. 1998; 862:87-99. [PubMed: 9928209]

3. http://www.lctglobal.com/lct-diabecell-diabetes-treatment.php and http://www.beehive.govt.nz/ release/living+cell+technologies+trial+approved

4. Yamada K, Yazawa K, Shimizu A, Iwanaga T, Hisashi Y, Nuhn M, O'Malley P, Nobori S, Vagefi PA, Patience C, Fishman J, Cooper DK, Hawley RJ, Greenstein J, Schuurman HJ, Awwad M, Sykes M, Sachs DH. Marked prolongation of porcine renal xenograft survival in baboons through the use of a 1,3-galactosyltransferase gene-knockout donors and the cotransplantation of vascularized thymic tissue. Nat Med. 2005; 11:32-34. [PubMed: 15619627]

5. Kuwaki K, Tseng YL, Dor FJ, Shimizu A, Houser SL, Sanderson TM, Lancos CJ, Prabharasuth DD, Cheng J, Moran K, Hisashi Y, Mueller N, Yamada K, Greenstein JL, Hawley RJ, Patience C, Awwad M, Fishman JA, Robson SC, Schuurman HJ, Sachs DH, Cooper DK. Heart transplantation in baboons using a 1,3-galactosyltransferase gene-knockout pigs as donors: initial experience. Nat Med. 2005; 11:29-31. [PubMed: 15619628]

6. Shimizu A, Yamada K, Yamamoto S, Lavelle JM, Barth RN, Robson SC, Sachs DH, Colvin RB. Thrombotic microangiopathic glomerulopathy in human decay accelerating factor-transgenic swineto-baboon kidney xenografts. J Am Soc Nephrol. 2005; 16(9):2732-2745. [PubMed: 16049072]

7. Schulte am Esch J, Rogiers X, Robson SC. Molecular incompatibilities in hemostasis between swine and men-impact on xenografting. Ann Transplant. 2001; 6:12-16. [PubMed: 11899892]

8. Wu G, Pfeiffer S, Schroder C, Zhang T, Nguyen BN, Kelishadi S, Atkinson JB, Schuurman HJ, White DJ, Azimzadeh AM, Pierson RN III. Coagulation cascade activation triggers early failure of pig hearts expressing human complement regulatory genes. Xenotransplantation. 2007; 14:34-47. [PubMed: 17214703]

9. Rees, MA. PhD thesis in Clinical Medicine and Clinical Veterinary Medicine. Cambridge, England: University of Cambridge; 2003. Immunological effects of hepatic xenoperfusion; p. 458

10. Naruse K, Tang W, Makuuch M. Artificial and bioartificial liver support: a review of perfusion treatment for hepatic failure patients. World J Gastroenterol. 2007; 13(10):1516-1521. [PubMed: 17461442]

11. Hering BJ, Wijkstrom M, Graham ML, Hårdstedt M, Aasheim TC, Jie T, Ansite JD, Nakano M, Cheng J, Li W, Moran K, Christians U, Finnegan C, Mills CD, Sutherland DE, Bansal-Pakala P, 
Murtaugh MP, Kirchhof N, Schuurman HJ. Prolonged diabetes reversal after intraportal xenotransplantation of wild-type porcine islets in immunosuppressed nonhuman primates. Nat Med. 2006; 12(3):301-303. [PubMed: 16491083]

12. Cardona K, Korbutt GS, Milas Z, Lyon J, Cano J, Jiang W, Bello-Laborn H, Hacquoil B, Strobert E, Gangappa S, Weber CJ, Pearson TC, Rajotte RV, Larsen CP. Long-term survival of neonatal porcine islets in nonhuman primates by targeting costimulation pathways. Nat Med. 2006; 12(3): 304-306. [PubMed: 16501570]

13. Fishman JA, Patience C. Xenotransplantation: infectious risk revisited. Am J Transplant. 2004; 4(9):1383-1390. [PubMed: 15307825]

14. http://www.transplantation-soc.org/sections.php?s=01.

15. Pierson RN III, Winn HJ, Russell PS, Auchincloss H Jr. Xenogeneic skin graft rejection is especially dependent on CD4+ T cells. J Exp Med. 1989; 170:991-996. [PubMed: 2504879] 